\title{
Cutaneous involvement by cytomegalovirus in a renal transplant recipient as an indicator of severe systemic infection ${ }^{*}$
}

\author{
Antonielle Borges Faria Neumann ${ }^{1}$ \\ Francielle Chiavelli Chiaratti ${ }^{1}$
}

\author{
Egon Luiz Rodrigues Daxbacher ${ }^{1}$ \\ Thiago Jeunon ${ }^{1}$
}

DOI: http:/ /dx.doi.org/10.1590/abd1806-4841.20163989

\begin{abstract}
Cytomegalovirus is an opportunistic virus that commonly affects immunosuppressed patients. Cutaneous involvement by this virus is rare and occurs in significantly immunocompromised hosts, with a poor prognosis. Skin ulcers may represent the first sign of systemic infection by cytomegalovirus in these patients. Herein, a case of a systemic infection by Cytomegalovirus presenting as genital and oral ulcers in a kidney-transplant recipient is reported.
\end{abstract}

Keywords: Cytomegalovirus; Immunocompromised host; Infection; Kidney transplantation; Skin ulcer

\section{INTRODUCTION}

Cytomegalovirus (CMV), also known as human herpesvirus type 5 , is a DNA virus that belongs to the betaherpes subfamily of the herpesviridae family, which are characterized by their latency ability. ${ }^{1}$ It may be transmitted by saliva, urine, sexual contact, placental transfer, breastfeeding, blood transfusion, solid organ or hematopoietic stem cell transplantations. After primary infection, the virus goes through a long latency period in the host. In immunocompetent individuals, primary infection is oftentimes asymptomatic, but it may manifest as a mononucleosis-like syndrome. On the other hand, in immunodepressed individuals, primary infection, reactivation of latent infection or reinfection by a different serotype usually cause the disease. ${ }^{2}$

Herein, a case of disseminated infection initially manifested only by worsening of renal function and the onset of skin and mucosa ulcers caused by the CMV is reported.

\section{CASE REPORT}

A 68-year-old male patient after a long time of essential hypertension progressed with hypertensive nephropathy, terminal renal failure and renal transplantation. He was in use of prednisone, tacrolimus and mycophenolate mofetil since the transplantion and presented decrease of renal function after two months requiring hospitalization. After admission, clean-based ulcers were noticed, one on the lateral border of the tongue and another on the dorsum of the penis (Figures 1 and 2). CMV infection was suspected and the work-up included antigenemia assay in peripheral blood and biopsies of the penile ulcer; one sample was submitted to histopathology and the other to polymerase chain reaction (PCR) for CMV. The histopathological examination revealed ulceration, occlusion of some vessels by thrombi and prominent endothelial cells with conspicuous cytoplasm and markedly enlarged nuclei containing CMV inclusion corpuscles, resulting in diagnosis of cytomegalovirus

\footnotetext{
Received on 16.09.2014

Approved by the Advisory Board and accepted for publication on 13.10.2014

Study carried out at the Hospital Federal de Bonsucesso (HFB) - Rio de Janeiro (RJ), Brazil.

Financial Support: None.

Conflict of Interest: None.

Hospital Federal de Bonsucesso (HFB) - Rio de Janeiro (RJ), Brazil.
}

(C)2016 by Anais Brasileiros de Dermatologia 
infection (Figures 3, 4 and 5). The qualitative PCR for DNA of the CMV was positive in skin samples, as well as the antigenemia assay on peripheral blood (Figure 6). The treatment with intravenous ganciclovir was started, with the dose adjusted in accordance with the renal function, but the patient died after 41 days of admission in consequence of pulmonary sepsis.

\section{DISCUSSION}

Cytomegalovirus (CMV) is an opportunistic virus that frequently affects immunosuppressed patients, such as those with HIV infection/acquired immunodeficiency syndrome and kidney transplant recipients. ${ }^{3,4}$ Active disease by CMV occurs most of the times in the first hundred days after transplant, at the moment of greater immunosuppression, representing an important morbimortality factor. ${ }^{2,4}$ It may manifest as a syndrome characterized by fever, atypical lym-

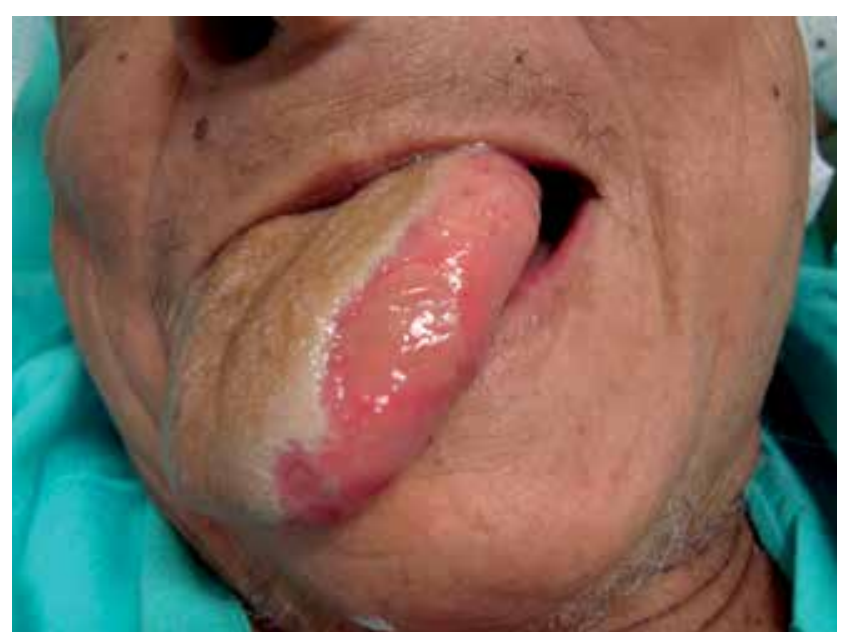

Figure 1: Clean-based, well-delimited ulcer on the lateral border of the tongue

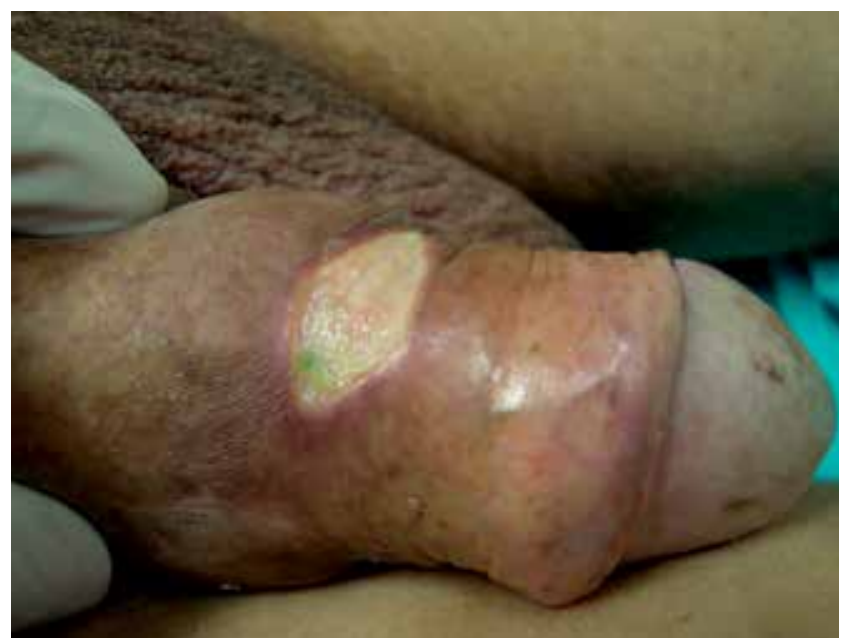

Figure 2: Clean-based, well-delimited ulcer on the dorsum of the penis

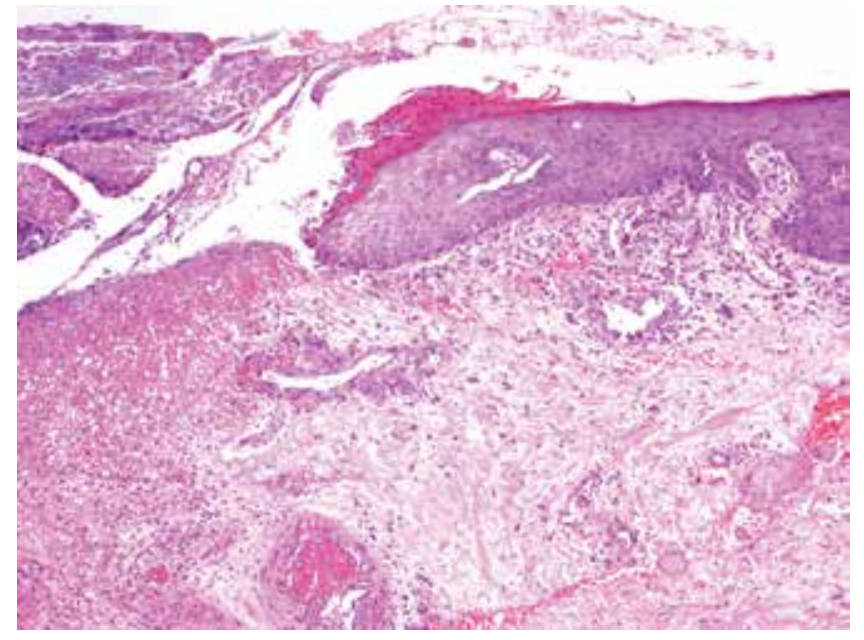

Figure 3: Partial surface ulceration and vessels with endothelial cells with large nuclei and ample cytoplasm, assuming an epithelioid aspect. In the lower part of the photomicrograph, a vessel occluded by a thrombus can be seen. HE, 100X

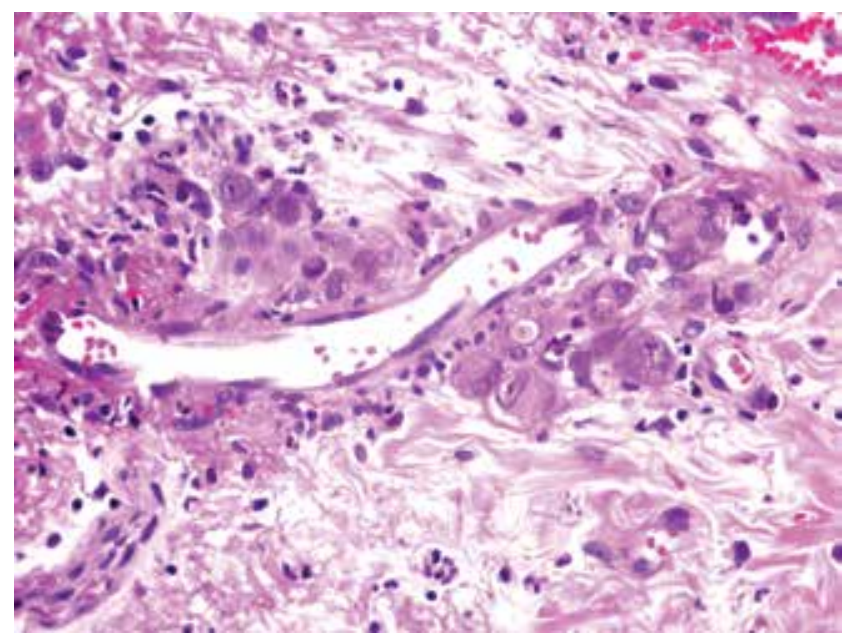

FIGURE 4: Endothelial cells with markedly augmented nuclei, rough nucleoli and ample cytoplasm. HE, 400X

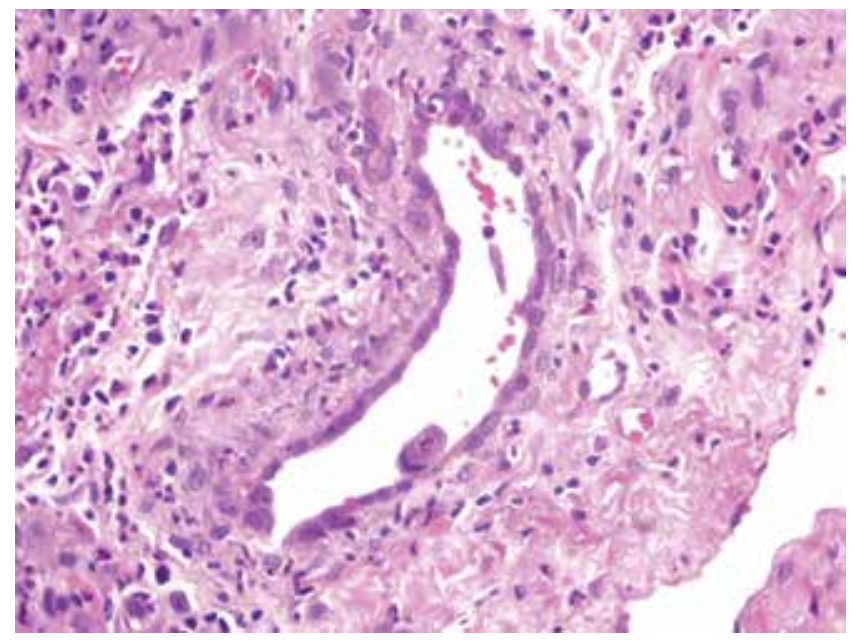

FIGURE 5: Eosinophilic corpuscle of viral inclusion, surrounded by a light halo in the cytoplasm of an endothelial cell with an epithelioid aspect. HE, 400X 


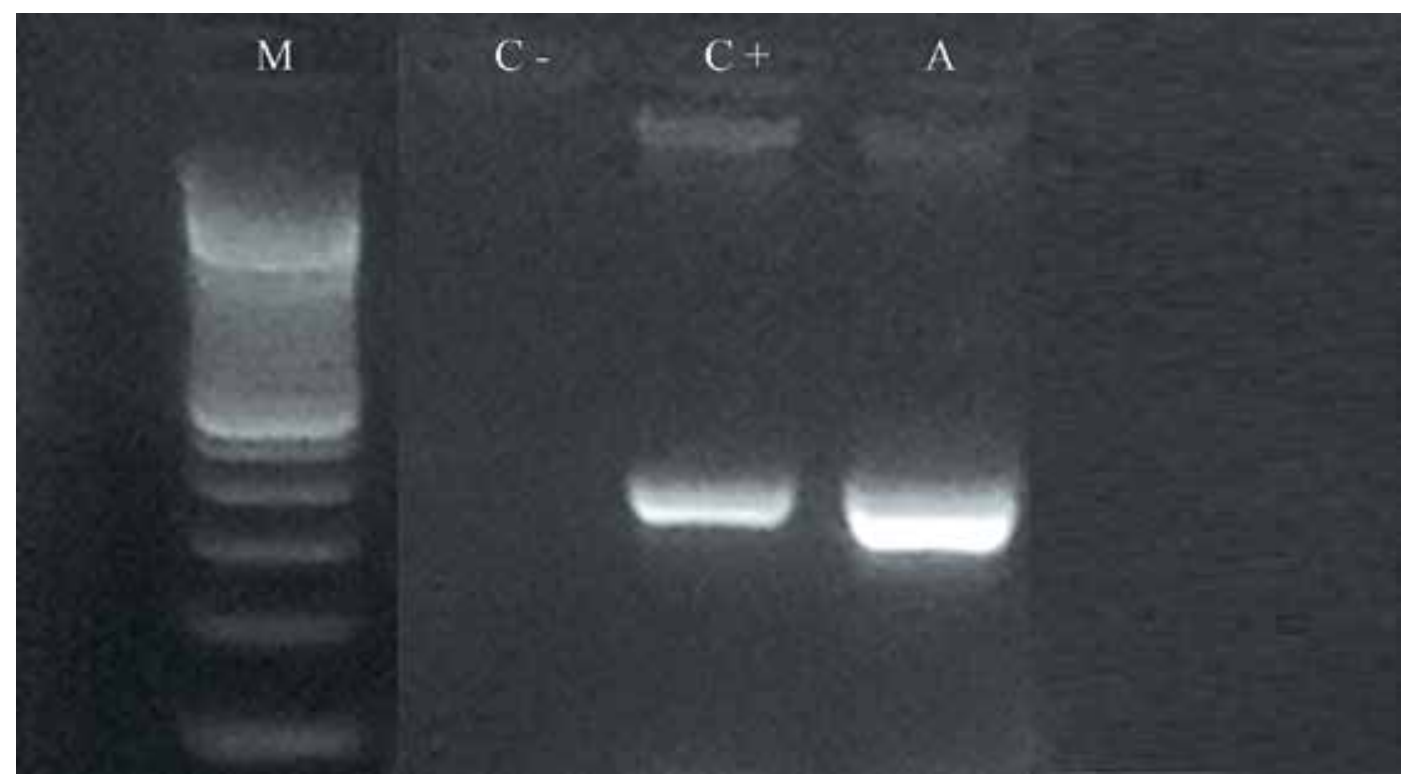

Figure 6: Agarose gel image after electrophoresis, with positive PCR results for DNA of CMV in the penile ulcer. M: Marker of molecular weight. C -: Negative control. C +: Positive control. A: Sample of the penile ulcer with a band at the level compared to positive control, which confirms the presence of DNA of the CMV in this sample

phocytosis, neutropenia or thrombocytopenia and malaise or as an invasive tissue disease. ${ }^{2,5}$ Although visceral manifestations by CMV are frequently reported, skin lesions caused by this virus are rare. ${ }^{3,5}$ In the present case, the patient in day 60 presented worsening of the renal function and ulcers of oral mucosa and skin of the penis.

The most frequent infectious dermatoses in renal transplant recipients are caused by fungi, followed by virus and bacteria; among the viral infections, there is a marked predominance of herpesvirus infection in the first year after transplantation, while warts usually appear later. ${ }^{6,7}$ It seems that the dermis is relatively inhospitable for the CMV and that the rare cutaneous involvement occurs only in significantly immunodepressed patients. Consequently, cutaneous lesions are usually associated with disseminated disease and predict a poor prognosis., ${ }^{3,4}$ CMV infection usually presents at the skin as a generalized maculopapulous eruption, but ulcers, nodules, vesicles, petechiae and plaques may come into being, mimicking other dermatoses, especially other infections. Ulcerations involving mainly the genital, perineal and perianal areas, as well as necrosis of mucosal membranes, may occur in more severe cases. ${ }^{4,8}$ Contrasting with what happens in lesions caused by herpes simplex or varicella-zoster, in which the cytopathic alterations (karyomegaly, peripheral chromatin margination and multinucleation) take place preferably in the epidermis and in the epithelium of hair follicles, the cellular alterations characteristic of infection by CMV involve preferentially the endothelial cells that line the small capillary vessels in the dermis. ${ }^{9}$ These present large nuclei and ample cy- toplasm, assuming an epithelioid aspect, and exhibit a rough eosinophilic inclusion corpuscle surrounded by a light halo, which may be present in the nucleus of the cell or located in the cytoplasm. Neutrophilic invasion of vessel walls is often observed, although unequivocal leukocytoclastic vasculitis is rare. Less frequently, the cytopathic alterations characteristic of CMV infection may be found in fibroblasts and macrophages, as well as in the epithelium of eccrine ducts and hair follicles. In congenital infections, extramedullar hematopoiesis may be found in the skin. ${ }^{8,9,10}$

There are two possible explanations for oral-genital ulcers caused by the CMV: the latent virus in the gastrointestinal tract, when reactivated, infects the skin of the perineum via fecal elimination, or reactivation of the latent virus in endothelial cells during the course of hematogenic dissemination. ${ }^{4}$ Infection by CMV also produces a vast range of indirect effects, such as decrease in function of the transplanted kidney, susceptibility to rejection and opportunistic infections. ${ }^{2}$ In the present report, the patient developed symptoms of pulmonary sepsis despite the use of intravenous ganciclovir. Because it was not possible to exclude a associated bacterial infection, systemic antibiotic therapy was promptly started. Nevertheless, the patient died after 41 days of admission in the hospital.

The infection is diagnosed based on the presence of typical clinical signs and symptoms and identification of characteristic inclusion corpuscles in histopathology, combined with detection of CMV in the blood and/or involved organs. ${ }^{3,4}$ At present, the methods of choice for such detection are antigenemia or PCR..$^{1-4}$ Antigenemia is a fast assay of semiquanti- 
tative immunofluorescence that detects phosphoprotein 65 produced by polymorphonuclear cells infected by CMV in peripheral blood. PCR detects viral DNA in total blood, leukocytes, plasma, serum or in the affected organ. ${ }^{2}$ In this case, we diagnosed the infection through histopathologic examination, antigenemia in peripheral blood and qualitative PCR in the affected skin. The infection should be treated with intravenous valganciclovir or ganciclovir until the replication of CMV is no longer detected, with a minimum of two weeks of treatment. Viral load monitoring should be done on a weekly basis, by means of PCR or antigenemia in peripheral blood. ${ }^{2}$

The dermatologist is of fundamental importance in a hospital where there is a renal transplant service. This case is an example of our role in the diagnosis and early treatment of severe diseases in the transplanted patient.]

\section{REFERENCES}

1. García-Testal A, Olagüe Díaz P, Bonilla Escobar BA, Criado-Álvarez JJ, Sánchez Plumed J. Análisis de infección por citomegalovirus y sus consecuencias en el transplante renal: revisión de uma década. Med Clin (Barc). 2011;137:335-9.

2. De Keyzer K, Van Laecke S, Peeters P, Vanholder R. Human cytomegalovirus and kidney transplantation: A clinician's update. Am J Kidney Dis. 2011;58:118-26.

3. Toome BK, Bowers KE, Scott GA. Diagnosis of cutaneous cytomegalovirus infection: A review and report of a case. J Am Acad Dermatol. 1991;24:860-7.

4. Moscarelli L, Zanazzi M, Rosso G, Farsetti S, Caroti L, Annunziata F, et al. Can skin be the first site of CMV involvement preceding a systematic infection in a renal transplant recipient? NDT Plus. 2011;4:53-5.

5. Prasad N, Jain M, Gupta A, Sharma RK, Agarwal V. An unusual case of CMV cutaneous ulcers in a renal transplant recipient and review of literature. NDT Plus. 2010;3:379-82.

6. Lima AM, Rocha SP, Reis Filho EG, Eid DR, Reis CM. Study of dermatoses in kidney transplant patients. An Bras Dermatol. 2013;88:361-7.

7. Vettorato G, Carvalho AVE, Lecompte SM, Trez EG, Garcia VD, Keitel E. Frequency of infectious dermatosis in 208 renal transplant recipients. An Bras Dermatol. 2003;78:283-288.

8. Lesher $\mathrm{JL} \mathrm{J}$. Cytomegalovirus infections and the skin. J Am Acad Dermatol. 1988;18:1333-8.

9. Requena L, Requena C. Histopathology of the more common viral skin infections. Actas Dermosifiliogr. 2010;101:201-16.

10. Resnik KS, DiLeonardo M, Maillet M. Histopathologic findings in cutaneous cytomegalovirus infection. Am J Dermatopathol. 2000;22:397-407.
MAILING ADDRESS:

Thiago Jeunon

Rua General Roca, 778/1005

Tijuca

20521-070 - Rio de Janeiro - RJ

Brazil

E-mail: thiago.jeunon@gmail.com

How to cite this article: Neumann ABF, Daxbacher ELR, Chiaratti FC, Jeunon T. Cutaneous involvement by cytomegalovirus in a renal transplant patient as an indicator of systemic infection. An Bras Dermatol. 2016;91(1):80-3 